\title{
Comparing the Satisfaction with the Banks E-payment Services between Degree Holder and Non-Degree Holder Customers in Penang-Malaysia
}

\author{
Alireza Chavosh, Anahita Bagherzad Halimi, and Shahriar Espahbodi
}

\begin{abstract}
- this study intends to investigate bank customer's satisfaction rate with e-payment services in Malaysia as many financial transactions are held by electronic payment systems in this country. Malaysian bank managers believe that the e-payment is of high potentiality to succeed as a new tool of payment which can increase the rapidity and accuracy of transactions and consequently increase customers' satisfaction. In this study, firstly, through a review of the literature issues associated with electronic payment along with its advantages are elaborated and discussed. Then a comparative analysis is provided by investigating the satisfaction rate with e-payment services in Malaysia's Banking Industry between two sample groups in Penang. These two groups consist of Degree Holder and Non-Degree Holder individuals who use electronic payment bank services in Penang. A sample size of 350 individuals was selected to answer the survey questions and then the collected data was analyzed by SPSS software. The findings from this study depicts that in spite of inconveniences, cost and some security concerns among Non-Degree holders about e-payment services and also some security concerns about such services among Degree holders, both groups of customers depicted a high level of satisfaction with e-payment services in Penang. In addition, inconvenience is found to be the most important issue which Non-Degree Holders were concerned about, while Degree Holders were more concerned about security issues. The results from this study can be used as a platform for bank managers and e-payment service companies in order to improve their systems and services in Penang, based on Malaysian consumers' needs and concerns.
\end{abstract}

Index Terms - e-payment satisfaction, e-payment services, banking industry, Degree Holders, Non-Degree Holders, Malaysia.

\section{INTRODUCTION}

Online transactions are the consequence of commercialization of internet along with advancement and evolution of e-commerce during the last decades. As e-commerce is being increasingly used worldwide, a number of different payment systems are developed in order to facilitate the exchange of money via internet for the customers. In this regards banking

Industry is one of the most important industries which has utilized e-payment systems as a means of financial

Manuscript received March 24, 2011; revised March 31, 2011.

F. A. Author is with the Faculty of Management, Multimedia University, Cyberjaya ,Malaysia (e-mail: vidranas@gmail.com).

S. A. Author is with the Faculty of Management, Multimedia University, Cyberjaya ,Malaysia (e-mail: chakameh.1983@gmail.com).

T. A. Author is with the Faculty of Management, Multimedia University, Cyberjaya ,Malaysia (e-mail: sh_espahbodi@yahoo.com). transaction that can provide customers with fast and convenient money transaction facilities. Nowadays, there are a broad range of financial services provided by banks over the internet, and banks are now competing toughly to equip themselves with updated electronic payment systems in order to better serve their customers and increase their satisfaction. In other words, in order to gain and maintain competitive edge banks are increasingly employing electronic payment systems which improves their services by providing customers with full time services and high-speed transaction facilities.

In general, utilizing web-based technologies and e-communications networks as means of payment is referred to as e-payment. Electronic innovations were firstly employed in 1980s and by 1990s banking industry was equipped with new electronic banking services. Today, electronic payment systems are spread in developing countries all around the world. In Malaysia also this trend can be obviously observed in a way that nowadays most of Malaysian banks are increasingly taking advantage of e-payment services. However, as e-payment is increasingly getting more significance in Malaysia's banking industry, investigating customers' satisfaction with electronic payment systems is of great importance to bank managers in order to improve their systems and services and adapt them with their customers' needs. On the other hand the rising competition in Malaysia banking industry compels bank managers to take advantage of cutting age technologies in order to survive in the industry. Therefore, e-payment as a fast, convenience and modern means of doing bank transactions can be utilized by banks in order to facilitate payment procedures and consequently increase customers' satisfaction. Nevertheless, a big challenge which is faced by Malaysian bank managers in offering e-payment services to their customers arise from the customer side which is the difference caused by the customers' different education levels in their propensity for using e-payment services via internet which ultimately affects their level of satisfaction. Studies have shown that less educated people are more reluctant in using electronic payment services as a result of their inconvenience in using internet for doing their transactions [2] and this may consequently affect their level of satisfaction with such services. In other words, people with higher education level are more adaptive to acceptance of e-payment banking systems [12], [14] and [18]. Hence, investigating the satisfaction of customers with different education levels, towards e-payment services in Malaysia is of great significance to banks in order to adapt their e-services with 
their customers' requests and survive in the highly competitive industry. Considering such importance, this study intends to investigate the satisfaction rate of Degree Holder and Non-Degree Holder bank customers using e-payment services within Penang-Malaysia.

\section{E-PAYMENT SERVICES ISSUES AND ADVANTAGES}

A review on the existing body of the literature shows that there are some issues as well as some advantages associated with e-payment services different customer's perspective. The most frequently mentioned issues consist of security and privacy concerns while advantages are identified as convenience, cost reduction and time reduction.

\section{A. Security and Privacy}

[13] Declared that security influences the customers' attitude towards online transactions. As there is no face-to-face contact in online transactions, a kind of uncertainty in most of the customers occurs. Consequently, more security is necessary in online transactions than traditional transactions. According to [20], security is one of the main concerns in business-to-consumer transactions. Additionally, [23] stated that security is the most important issue in online service quality. On the basis of [11] study, security of websites significantly impacts the consumer's attitude towards online purchasing. [17] also believe that a customer's perception of Web security influences his/her acceptance of web-based transactions. Besides, privacy and security concerns are among the 10 most significant barriers in online purchasing adoption [4]. In online transactions, customers need to give their credit card information and this is the most important cause of the security concern in E-commerce transactions [8]. Therefore, customers avoid doing online transactions as it accompany security risk [10]. [8] study found out that, customers desire to pay more money for secure and trusted online shopping websites.

Besides security concerns customers are facing privacy issues as well. When customers do online transactions, they are sometimes required to give their personal information, for example, their name, telephone number and credit card number. Accordingly, consumers principally need to give their private information in order to perform any transaction; for that reason many consumers decline to do transactions online because of some privacy matters. Privacy concerns comprise offensive data admittance, data compilation, and unauthorized data usage [22]. [21] also determined privacy as an essential issue in designing online shopping websites. According to [19] study, making privacy available for customers on websites impacts their trust on the seller's website as they do online purchasing. Internet retailers' attempt to build a "secure" image is a significant factor to persuade customers to do online purchasing. Banks could make several strategies that decline the customer's concerns related to their privacy. It is possible for them to persuade their customers to enhance their experience and awareness regarding Internet and online transaction protocols. Hence, security and trust are main factors which should be greatly considered in online business transactions. They extremely influence the consumers' attitude towards online purchasing and transaction [9]. According to prior studies, customers may give up online shopping when they should give their personal information because of privacy concerns. Privacy concern greatly depends on some individual differences, for instance education, and culture [7] \& [19].

Regarding security and privacy issues associated with internet banking, [25] introduce "perceived credibility" as a new factor of technology acceptance model (TAM) variable that reflects the user's security and privacy concerns in the acceptance of Internet banking. According to the TAM, the intention to use a particular system determines the customers' adoption behavior. The system, in turn, is determined by the perceived usefulness and perceived ease of use of the system. Perceived risk is associated with the personal prospect of the consumer about bearing a detriment in quest of a planned upshot. It has a multi-dimensional construct with overall risk which is subdivided into performance, physical, financial, psychological, social loss, and time. Hence, it is relatively difficult, in the Internet banking context, to define conceptually and discriminate every risk dimension, and to identify the potential risk dimensions that may influence users' acceptance of Internet banking. Impersonality, reliance upon degree of reputation and dependence on economical and financial factors are the most important characterizes of Perceived credibility. Indeed, perceived credibility is a new construct to reflect the security and privacy concerns over the acceptance of Internet banking. Overall, computer self-efficacy has the major influence on the intention of an individual to use Internet banking through perceived usefulness, perceived ease of use, and perceived credibility.

[5] argued that issues in online security is the theme of Online Information Review, for one very good reason online security, or more properly breaches in online security, is a rapidly-spreading parasite that characterizes the present decade. Within the e-environment, the degree to which consumers and business trust each other forms a key element of the contest; this is a significant enough issue to warrant security with distinctive views on how this trust can be enhanced. The lack of consumer trust has been traditionally considered a major factor that prevents a more rapid development of the online transactions and commercial relationships. In order to create and expand such trust obtaining strong privacy and security features is of great importance. There is considerable uncertainly on the part of consumers because there is no face-to-face transaction, and payment is made by credit card before the goods are delivered.

[27] Presented a practical electronic payment protocol over the internet. Regarding privacy issues, customers do not want their transaction be recorded or their sensitive information is cleared by others. Anonymity mostly is provided by a third party guarantee these days. The protocol which is presented in the article tries to handle disputes automatically without manual intervention. Moreover, the proposed protocol guarantees anonymity of both the customer and merchant. The third solution provided by the protocol is that there is no reliance on the third party to realize desired functions. First, the customer sends an encrypted payment token to the merchant. The token contains the financial instruction to credit the relevant account with an 
amount equal to the cost of subscription. A copy of this token encrypted with a second key that bears a mathematical relation with the first key received by the merchant. The encrypted messages match if the unencrypted messages match. Customer's bank sends an encrypted message with the second key to the merchant's bank. Validity of the payment is ensured after the merchant compares forms of the token received from the customer and the merchant's bank. The decryption key of the payment will be send to the merchant after the customer receives the product. Finally, the merchant can decrypt the token and arranges the settlement. The proposed system increase efficiency, reduce cost and provides ease-of-use. Since third party is not involved, usability of the system is increased while communication overhead is decreased. By the introduction of "commit buffer" concept, merchants can check orders once an hour rather than responding every customer immediately. In addition, communication between banks will be done only once a day that decreases the costs even more because of cost reduction in operating and designing the system. It can be interfered that the action is more practical and real than any other system and the protocol applies a fair-exchange technique to the process of purchase and physical delivery via an ecommerce system while there is no involvement of third party and customer and merchant anonymity is maintained.

[1] Proposed a framework for easy security incorporation in credit card based electronic payment system without the use of an on-line third- party processor to deduct cost and improve effectiveness in the developing nations. When a third party is used in a payment system based on credit card, verification of the electronic transaction incurs extra costs. Moreover, complexity and excessiveness cost associated with the use of third party prevent the buyers and sellers in most of the developing countries to use the system. Two parties are handling the transaction. One party is the credit card providers, charge card providers, debit card providers, digital card providers and private label card providers and even the Internet Service providers; other party is the service provider for on-line transactions. Card providers make cards available in different stores. A unique ID is given to each card provider. Information about the card provider ID, secret number / text, balance and the like all included in the card. Each company maintains a server to listen on a defined port for the Credit Requests and a database on the sold cards from where the credits will be made. Card providers are responsible to prepare the card and make them available and will charge the users differently based on the amount of each card. When the consumer purchases the product through the web server of the service provider, he has to enter card number, password and card provider ID. Then he sends a request for crediting to the card provider company. The service provider processes the data about the customer balance and after getting clearance, the record of the transaction is kept in the form of digital signature by service provider and credit is deduced in card sellers' database. A copy of the digital signature is stored on the credit card provider side to prevent demand for money by the service provider at the end of the month. To prevent hacking, a firewall is in place between the card provider and the service provider. There are some advantages such as removing the third party in online transaction, inexistence of performance bottleneck, and dealing with micro transactions. However, capability of vendor for establishing secure communication with consumers' browser and communicating with underlying databases holding the digital signature, and capability of card producer to handle secure credit requests the ability to communicate with the database storing digital signature and sold cards' information are implementing issues for the framework. In short, it can be mentioned that this is the best way to open up e-commerce transaction in developing counties if the authorities of the developing countries exploit the proposed framework.

[26] Tried to improve the e-payment system with a smart card and offered an anonymity-revoking e-payment system. Participants' anonymity in a transaction can be kept by using cryptographic tools such as blind signatures. However, such systems can be misused by criminals for money laundering. There is trustee, trusted third party, which is involved in the transaction and is able to remove the anonymity of a transaction if the system is misused by criminals. The trustee in corporation with the bank is able to identify the owner after making payment. He can also determine the cash withdrawn from the bank and link it to the purchase. In case anonymity revocation is needed, the trustee can link a withdrawal transaction with the corresponding deposit transaction. There are two ways by which anonymity revocation can be done. The first way is when the trustee can compute a piece of information based on the bank's view of a withdrawal transaction to recognize the money when it is spent later. When the account owner is forced to withdraw money to an anonymous criminal, the bank will be informed by the owner and the trustee is asked to compute a value which can be put in a black list, so the money can be recognized as soon as it is spent. In the other method, the trustee computes a parameter that can be linked by the bank to the corresponding withdrawal based on the bank's view of a deposit transaction. In general the protection of the legal users' anonymity is done by the payment protocol and deposit protocol. The user's privacy is not threatened neither by the bank not by the merchants even after they collaborate with each other. It can be seen that the third party can link a payment to a corresponding withdrawal and prevent money laundering and blackmailing.

\section{B. Convenience, cost reduction and time reduction}

\section{1) Convenience}

Convenience is a very important factor for attracting users. Perceived ease of use and perceived usefulness are the two main factors for users' attitude, intention and actual adoption of e-payment system. Ease of use is especially important for those who use computer for the first time, like old people and illiterates, because they will avoid working with the complicated systems. It is noticeable that increased ease of use over time leads to improve performance. However, there are still some cultural barriers to empower users to make purchases without any formal approval process. In addition, persuading some suppliers, especially smaller ones, to accept cards and electronic type of payment in general due to the associated transaction costs for the supplier or even security 
of their transactions seems difficult. Payments of bills through electronic payments to the government are the best way to prove that e-payment can bring convenience to people. M-Government has proven that it is wrong to believe that citizens are unwilling to pay for government services. People are not only paying to get basic information needed to deal with the bureaucracy, they are also willing to spend to bring their concerns before the appropriate officials. Payments of bills through electronic payments to the government are the best way to prove that e-payment can bring convenience to people. M-Government has proven that it is wrong to believe that citizens are unwilling to pay for government services. People are not only paying to get basic information needed to deal with the bureaucracy, they are also willing to spend to bring their concerns before the appropriate officials. Tax collection has always been a problem in most of the countries. E-payment of tax is a facility provided to the tax payers to make tax payments through internet using net-banking facility. Through electronic payment of taxes, the government can find whether the payment is done or not. There are also some incentives that can be provided with the government and banks such as senders are charged the lowest price for a text message sent to government. In electronic commerce, factors such as navigational characteristics, virtual characteristics, and practical considerations (including images, background, color, sound, video and media) are important issues considered by customers in evaluation of the website especially from convenience perspective.

\section{2) Cost and time reduction}

Financial institutions should decide upon implementing e-banking products and services by a thorough analysis of the costs and benefits associated with such action. The individuals who do the cost-benefit analysis should clearly understand the risks associated with paying electronically so that cost considerations fully include appropriate risk controls. Without clearly defined and measurable goals by banks, determining the customers' needs is necessary. When a customer evaluates cost/ benefit of a transaction, he or she should find the electronic payment facility an appropriate way of doing business. Due to reduction in paper handling of purchase orders and invoices there are some cost reductions inefficiencies. Moreover, management of information is more and better on spending than when using paper based systems. When a customer evaluates cost/ benefit of a transaction, he or she should find the electronic payment facility an appropriate way of doing business. Due to reduction in paper handling of purchase orders and invoices there are some cost reductions inefficiencies. Moreover, management of information is more and better on spending than when using paper based systems.

Regarding convenience, cost reduction and time reduction there are a number of argues within the existing body of literature. [15] argued that mobile banking services are valued by users because of the inherent time and place independence, using technology and services emerged of the technology, and finally the overall effort-saving qualities. Mobile banking, firstly, provides customers with easy access to their account balance through SMS. The new Wireless Application Protocol (WAP) and Java-enabled mobile phones using General Packet Radio Service (GPRS) support a wider variety of services offered by banks such as stock trading, transaction of fund between accounts, direct payment confirmation through the micro browser of the phone. Indeed, banks are interested in supporting their smart card standards (EMV) in the mobile environment. Hence a more rapid, user-friendly, convenient, available and less costly mobile payment facility will provide both customers and banks with many advantages.

[24] Analyzed the experience of creating and implementing a unique e-government payments system (called Gordo) in Siberia. At first, Gorod was used by local governments to collect housing and utility services (HCS) payments. Then it changed to a unique public-private partnership to gather information from service providers and created a consolidated bill which could be paid by person, through the internet, via cell phone and through ATM. The best characteristic of Gorod is that it is easy to use, to try out and to observe and it needs almost no changes in users' behavior. It has a strong relative advantage in time savings, highly compatible with the Russian mentality. Collection rates by using Gorod are now 90-99 percent depending on the supplier. The services to be paid in electronic payments should be linked by the service center to cardholder's account. People purchase plastic (credit) cards for electronic payments and are charged for account inquiry and electronic payments. A system like Gorod can only succeed by the sufficient adoption of service providers, agents, and municipalities. The bank should have willing to take on substantial hardware, Oracle and Gorod software and telecommunication costs. While Gorod collects payments in most city, regional, or state payments, in some cases it is not legal to take commissions for tax payments; thus, banks are not interested in these payments. Other banks can be considered as agent by banks with exclusive rights if they meet favorable terms. Gorod in cities with public-private control functions as a form of a state-endorsed standard with incentives on all sides for its adoption. This form of arrangement ensures e-payment system adoption. In the development of e-government usually e-payment is seen as a later stage of e-government as a part of the evolution from e-information to e-services, but it has a very important role from the beginning. Mid-level DIT is applied initially for the formation of a standard around the technology in case of complex, multi-party innovations. Initial adoption of systems like Gorod does not need a widespread internet use, automation of data processing in the city or even the adoption of electronic banking. It is an easy transition to each of places or states that participating in the system. Gorod users would be able to pay for everything they owe, electronically, on one bill. It can be as a tool for data collection and service provision for municipalities. Gorod is an instantaneous way for electronic payment to any service for service providers. It seems a system like Gorod is quite good for developing countries and will pave the way for implementation of an electronic government. [16] Explored why some retail banks more than others are vigorous in their promotion and have been successful in changing their distribution channel structure through introducing new electronic channels such as PC banking and Internet banking. Furthermore, the results indicate that different attitudes and 
perceptions are related to different means of attracting customers to the electronic channels. The new electronic channels provide the customers with better service output in the form of a broader and deeper assortment with less waiting time, and higher market decentralization. They are more cost-effective than telephone and branch-based networks, so lower costs may lead to lower prices for the consumers.

\section{Population AND SAMPle Size}

The population of this study is all individuals over 24 years old who live in Penang and have bank account in one or more local or foreign banks located in Penang. A sample size of 350 individuals was then selected to answer to the survey questions. After distributing the questionnaire among the bank customers and collecting the answers within period of one week a number of 304 questionnaires were distinguished complete and useful among which 218 customers were assessed as Degree Holder individuals while 86 of respondents were distinguished as Non-Degree Holder individuals . Later by using SPSS 16 the collected data was analyzed.

\section{E-PAYMENT SERVICES IN MALAYSIA}

E-payment services in Malaysia include a wide range of services provided by different Malaysian and Non-Malaysian banks in this country. This provides Malaysian customers with a variety of e-payment methods such as credit cards, debit cards, electronic wallet, mobile payment-checks and the Automated Clearing House network (consisting of direct deposit, direct debit and e-checks) and etc. These services are offered all around the country by Malaysian and non-Malaysian banks. In Penang also, as one of the most important cities in Malaysia, e-payment services are broadly used by customers in their daily money transactions. Due to the rising competition among banks in attracting and retaining customers, the number and variety of e-payment services offered by banks are increasing and more customers are now using such systems in Penang. Therefore investigating the Malaysian customers' satisfaction with e-payment services is of great importance to banks in order to improve their services based on their customers' needs and wants and survive in the industry. In this study the satisfaction of Malaysian bank customers with e-payment services is compared between two groups of Degree Holder and non-Degree Holder individuals. The survey instrument employed in this study is a simple questionnaire consisting of 8 questions.

\section{QUESTIONNAIRE}

A simple questionnaire was designed for the purpose of this study in three parts. The first part of questionnaire was used to collect demographic data such as age, gender, level of education, religion and ethnicity. The second part of the questionnaire was designed with the purpose of collecting data about e-payment satisfaction of Malaysian bank customers in Penang as below:

1) I use e-payment services provided by banks in Penang.

2) I believe that electronic payment services are better than traditional ones.

3) I believe that electronic payment services are less costly than traditional ones.

4) I believe that electronic payment services are faster than traditional ones.

5) I believe that electronic payment services are more convenient than traditional ones.

6) I believe that electronic payment services are more secure than traditional ones.

7) I believe that electronic payment services have higher levels of customer privacy than traditional ones.

8) I am really satisfied with electronic payment services provided by banks within Penang.

Respondents were asked to choose one of the five-point liker scale alternatives ranged from Strongly agree to Strongly disagree.

In the third section of the questionnaire respondents were asked whether they prefer e-payment systems to traditional ones.

In addition, the reliability of the questionnaire was tested. The values of Cranach's Alpha for questionnaire, was estimated 0.865 which is a strong and acceptable value. The validity of the questionnaire was also approved by two academics in field of marketing management.

\section{SURVEY}

The first group of respondents in this study (Degree Holder Customers) consists of $38 \%$ women and $62 \%$ men. The second group (Non-Degree Holder Customers) includes $29 \%$ women and $71 \%$ men (Figure 1 ). $83 \%$ of either groups were under 50 and over 24 while the rest $(17 \%)$ were over 50 years old. Fig 1 depicts the percentage of male and female in both Degree Holder and non-Degree Holder customer groups.

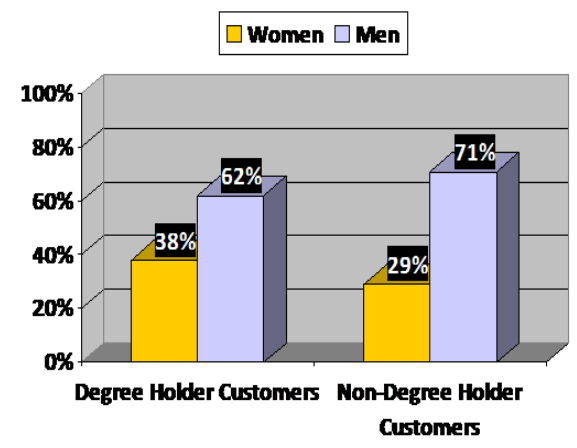

Fig 1: The percentage of male and female in both Degree Holder and non-Degree Holder customer groups

\section{RESULTS}

In this section a detailed analysis of each of the questions within the second part of the questionnaire is presented.

The first question was propounded to understand the rate of e-payment users and non-users in both groups. The average calculated for the first group (Degree Holder Customers) was 4.68 and for the second group was 4.16.This result indicated that although the first group have a higher average of usage, there is not a significant difference between the level of e-payment services usage among Degree Holder and non-Degree Holder customers of banks located in Penang. 
For the second question the average calculated for the first group was 4.14 and for the second group 3.40 which is higher than Undecided. This shows that the e-payment services are better for Degree Holder customers. The results also indicated that Non-Degree Holder Customers have motivation to e-payment services more than traditional services.

The results from the third question indicated an average of 4.80 for Degree Holder Customers and 2.93 for Non-Degree Holder Customers. It can be concluded that Degree Holder Customers strongly believe that e-payment services can reduce cost of transactions in comparison to traditional payment services offered by banks. The results also showed that Non-Degree Holder Customers believe that e-payment services are not cost effective in comparison to traditional services and may even be more costly.

The result from the fourth question of the survey is considerable. An average of 4.59 was resulted for the first group of customers while the result for second group was 4.67.This indicated that Non-Degree Holder Customers believe that e-payment services are faster than the traditional ones while Degree Holder Customer supported this idea to a lower extent.

Outcomes from fifth question show an average of 4.52 for Degree Holder Customers and 2.46 for Non-Degree Holders. This illustrates that Non-Degree Holder Customers are not feeling convenience in using e-payment services while Degree-Holder Customers conveniently use this type of services.

The sixth question showed a result of 3.91 for Degree Holder Customers and 3.23 for Non-Degree Holder Customers. It can be inferred that both group of customers do not believe in a very high security of e-payment services. However, Degree Holder Customers showed a higher level of trust in such services.

The seventh question which investigated the customers' beliefs about the customer privacy level of e-payment services had a surprising result. A 4.43 average for first group of customers versus 4.83 for the second group depicted that in terms of customer privacy Non-Degree Holder Customers believed in a higher level of privacy provided by banks in electronic payment systems than traditional ones.

The last question showed another interesting result. An average of 4.35 Degree Holder Customers depicted satisfaction with e-payment services in Penang. However, an average of 4.26 was calculated for the Non-Degree Holder Customers in this respect. This indicated that both group of customers were satisfied with e-payment services offered by banks located in Penang (Fig. 2).

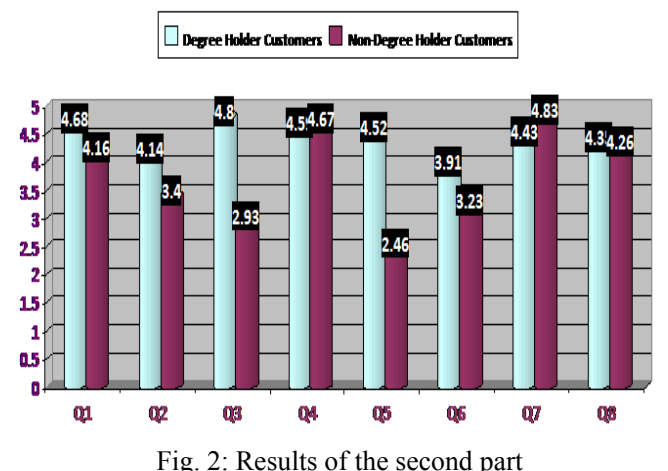

Fig. 2: Results of the second part
The results from the last part of the survey instrument depicted that $89 \%$ Degree Holder Customers preferred e-payment services to traditional ones. In addition, $73 \%$ of Non-Degree Holder Customers preferred e-payment services as well.

\section{RESEARCH LIMITATIONS}

This study is conducted in Malaysia and as a result the findings are based on the Malaysian culture and environment. The time and cost limitation also can be consider as another constraint in collecting data for the study. Therefore the population of the study was geographically limited to Penang and a further study can be conducted in other parts of Malaysia especially in Federal Territory (Kuala Lumpur).Another limitation was the poor level of English language understanding among Non-Degree Holders in Penang which compelled the authors to design a questionnaire in Bahia Malaysia language.

\section{Study CONTRibutions}

This study contributes to bank managers, online transaction facility provider companies and software developer firms in understanding the customers concerns and issues while using e-payment systems in Malaysia and other developing countries. Understanding such issues will help banks to equip their e-services with more advanced and user-friendly electronic payment systems which ultimately lead to higher levels of satisfaction among customers from different education backgrounds.

\section{CONClusion}

It can be obviously concluded that the most important issue for Non-Degree Holder Customers in using e-payment services is feeling inconvenience in working with such services. However the results showed that in spite of the existence of inconveniences, this group of customers use e-payment banking services to a large extent regardless of the high cost and also some security issues associated which such services, because they believe that these services are faster and provide them with higher level of privacy in comparison to traditional services. As well as Degree Holder Customers, this group depicted a high level of satisfaction with e-payment services and declared that they prefer such services to traditional ones. On the other hand, based on the results from data analysis Degree Holder Customers showed that they prefer e-payment services to traditional ones in all aspects and their only concern is to some extent about the security issues in using such e-services. The findings from this study are in consistence with those of [3] and [2] as this study illustrated that less educated people face a high level of inconvenience in using e-payment systems. Security is also another issue identified by this study which both groups of customers are concerned about. This is in consistent with the study by [6] which identified the security risk associated with electronic payments as one of the two key factors which can prevent customers from using electronic payment services. 
Hence security issue must be considered more carefully by bank managers and e-payment service providers in Malaysia.

\section{REFERENCES}

[1] Anik, A. A., and Pathan, A.-M. K. (2005), "A Framework for Managing Cost effective and Easy Electronic Payment System in the Developing Countries", Department of Information and Communication Engineering,and Computer Science and Information Technology, The University of Tokyo, arxiv.org/pdf/cs/0605063.

[2] Amrit Banstola, 2007. "Prospects and Challenges of E-banking in Nepal," Journal of Nepalese Business Studies, Vol. IV, No. 1

[3] Dickerson, M. D. and Gentry, J. W. (1983). "Characteristics of Adopters and Non Adopters of Home Computers." Journal of Consumer Research, 10 (2): 225-235.

[4] Ernst \& Young LLP. (1999). The Second Annual Ernst \& Young Internet Shopping Study: The Digital Channel Continues to Gather Steam. Washington, D. C.: National Retail Federation.

[5] Gorman (2007), "Who am I, and where's my money? Issues in online security", Online Information Review Vol. 31 No. 5, 2007, pp. 561-565.

[6] Gerrard, Cunningham and F. Devlin (2006), "Why Consumers Are not Using Internet Banking: a Qualitative Study", Journal of Services Marketing 20/3, pp.160-168.

[7] Hsu, C. W. (2006). Privacy concerns, privacy practices and web site categories toward a situational paradigm. Online Information Review, 30(5), 569-586.

[8] Jarvenpaa, S.L. and Todd, P.A. (1996-97). Consumer Reactions to Electronic Shopping on the World Wide Web. International Journal of Electronic Commerce, Vol.1 (2), pp.59-88.

[9] Jarvenpaa, S.L. Tractinsky, N. Saarinen, L. \& Vitale, M. Consumer Trust in an internet store: a cross-cultural validation, Journal of Computer-Mediated Communication 5 (2) (1999) (online).

[10] Koyuncu, C. and Bhattacharya, G. (2004). The Impacts of Quickness, Price, Payment Risk, and Delivery Issues on On-line Shopping. Journal of Socio-Economics, Vol.33, pp.241-251.

[11] Liao, Z., \& Cheung, M. T. (2001). Internet-based e-shopping and consumer attitudes: An empirical study. Information and Management, 38(5), 299-306.

[12] Mattila, M., Karjaluoto, H. and Pento, T. (2001) "Internet banking adoption factors in Finland,"Journal of Internet Banking and Commerce, Vol. 6, No1.

[13] McCartney, L. (1997), “A Safety Net”, Industry Week, pp. 74-78.

[14] Matilla, M., Karjaluoto, H. and Pento, T. (2003) 'Internet banking adoption among mature customers: early majority or laggards?', Journal of Services Marketing, Vol 17, No. 5, pp.514-528.
[15] Mallat, N., Rossi, M., Tuunainen, V. and Öörni, A. An empirical investigation of mobile ticketing service adoption in public transportation Journal Personal and Ubiquitous Computing Springer, London, 2006.

[16] Niels Peter Mols, (2000) "The Internet and services marketing - the case of Danish retail banking", Internet Research, Vol. 10 Iss: 1, pp.7 18.

[17] O'Cass, A., \& Fenech, T. (2003). Web retailing adoption: Exploring the future of Internet user's web retailing behaviour. Journal of Retailing and Consumer Services, 10(2), 81-94.

[18] Polatoglu, V.N. and Ekin, S. (2001) 'An empirical investigation of the Turkish consumers' acceptance of internet banking services', International Journal of Bank marketing, Vol. 19, No. 4, pp.156-165.

[19] Peslak, A. R. (2006). PAPA revisited: A current empirical study of the mason framework. The Journal of Computer Information Systems, 46(3), 117-123.

[20] Ranganathan, C., \& Ganapathy, S. (2002). Key dimensions of business-to-consumer web sites. Information and Management, 39(6), $457-465$.

[21] Ramayah, T \& Jantan (2003). Intention to Purchase through the World Wide Web (WWW): The Malaysian Experience. The Third International Conference on Electronic Commerce Engineering (ICeCE2003), Hangzhou, China.

[22] Swaminathan, V., Lepkowska-White, E., \& Rao, B. P. (1999). Browsers of buyers in cyberspace? An investigation of factors influencing electronic exchange. Journal of Computer-Mediated Communication,5(2).http://jcmc.indiana.edu/vol5/issue2/swaminathan .htm.

[23] Wolfinbarger, M., \& Gilly, M. C. (2003). eTailQ: Dimensionalzing, measuring and predicting etail quality. Journal of Retailing, 79, $183-198$.

[24] William, M., H. and Artem, B (2005), "E-government Public-private Partnerships: the Gorod Payments System in Siberia", The Journal of Enterprise Information Management Vol. 18 No. 5, 2005 pp. 625-640.

[25] Wang, Wang, Lin and Tang (2003), "Determinants of User Acceptance of Internet Banking: An Empirical Study", International Journal of Service Industry Management, Vol. 14 No. 5, 2003, pp. 501-519.

[26] Yang, B. , Liu,D. and Wang,Y.,(2002) "An Anonymity-revoking E-payment System with a Smart card", International Journal on Digital Libraries ,Volume 3, Number 4, 291-296.

[27] Zhang Q., Markantonakis K. and Mayes K. (2006), “A Practical Fair-Exchange E-Payment Protocol for Anonymous Purchase and Physical Delivery", The ISG-Smart Card Centre, Founded by Vodafone, G\&D and the Information Security Group, Royal Holloway, University of London, www.scc.rhul.ac.uk/public/295_Zhang.pdf . 